\title{
Micros, pequenas e médias empresas: atores importantes no espaço regional do Mercosul?
}

\section{Micro, small and medium enterprises: key players of the Mercosur regional space?}

Jacqueline A. Haffner-Professora do Departamento de Economia e Relações Internacionais (DERI) e do Programa de Pós-graduação em Estudos Estratégicos Internacionais (PPGEEI) da UFRGS. Integrante do Grupo de Pesquisa sobre os BRICS (NEBRICSUFRGS). Mestrado e Doutorado em História pela PUC do Rio Gran do Sul/PUCRS. E-mail: Jacqueline.haffner@ufrgs.br

Leandro Teixeira dos Santos - Doutorando e mestre em Estudos Estratégicos Internacionais - PPGEEI/UFRGS. Integrante do Núcleo de Estudos do BRICS (NEBRICS-UFRGS) e bolsista CAPES. E-mail: teixeirasantospe@gmail.com

Nadia B. Menezes - Doutoranda em Estudos Estratégicos Internacionais - PPGEEI/ UFRGS - Bolsista FAPERGS/CAPES. Integrante do Grupo de Pesquisa sobre os BRICS (NEBRICS-UFRGS). E-mail: nadiabmenezes@yahoo.com.br

\section{Resumo}

A temática desse artigo é o papel de Micro, Pequenas e Médias Empresas (MPME) em países membros do Mercado Comum do Sul (MERCOSUL). Objetiva-se responder à questão: As MPME constituem atores relevantes na consolidação do espaço regional conformado pelas economias mercosulinas? A hipótese é que sim. Após destacadas as diferentes conceituações desses atores e enfatizadas as suas relevâncias enquanto promotores do crescimento econômico e do desenvolvimento social em cada Estadoparte - a partir de revisão da literatura e da análise de dados - encontram-se evidências que permitem confirmar a hipótese.

\section{Palavras-chave}

Mercosul. Integração Regional. Micro. Pequenas e Médias Empresas.

\begin{abstract}
The theme of this paperis the role of Micro, Small and Medium Enterprises (MSMEs) in member countries of the Southern Common Market (MERCOSUR). It aims to answer the question: The MSMEs are important actors in the consolidation of the regional space conformed by the mercosulinas economies? The hypothesis is that yes. After highlighted the different conceptualizations of the seactorsand emphasize their relevance as promoters of economic growth and social development in each State-part - from literature review and data analysis - evidences are allowing confirm the hypothesis.
\end{abstract}

\section{Keywords}

Mercosur. Regional Integration. Micro. Small and Medium Enterprises. 


\section{INTRODUÇÃO}

A história mostra que não há caminhos para o desenvolvimento sem maior integração com o mundo e sem ocupação do espaço regional. Observase que, no longo período que vai desde a Segunda Guerra Mundial até os dias de hoje, poucos países conseguiram entrar no âmbito dos países desenvolvidos. Tem-se a certeza sobre serem os países que se destacaram internacionalmente os que seguiram o caminho da maior integração comercial.

Nota-se que, embora não exista uma forma única de propiciar a maior inserção de um país na economia internacional, é importante observar as evidências econômicas que fazem refletir sobre a relevância das empresas nesse sentido, principalmente o papel que as micro, as pequenas e as médias empresas (MPME) têm nos diferentes países do mundo. Justifica-se, igualmente, a importância do artigo por lançar luz ao debate relativamente esquecido em muitos estudos, principalmente nas áreas de administração e economia.

Por isso, a temática desse artigo é o papel de MPME em países membros do MERCOSUL. Objetiva-se responder à questão: As MPME constituem atores relevantes na consolidação do espaço regional conformado pelas economias mercosulinas? Assume-se como hipótese que sim. Metodologicamente, a problemática é abordada por meio de revisão da literatura e pela exposição e análise de dados. Após destacadas as diferentes conceituações das MPME e enfatizada a sua relevância enquanto promotoras do crescimento econômico e do desenvolvimento social em cada Estado-parte, encontram-se evidências que permitem confirmar a hipótese.

Estruturalmente, para atingir o objetivo central apresentado, divide-se o artigo em quatro partes além dessa introdução. A seção 2 compreende o quadro teórico-conceitual. A seção 3 traz a revisão da literatura, destacando de forma geral a importância das MPME enquanto promotoras de crescimento econômico e desenvolvimento social, assim como os seus valores para a integração regional. A seção 4, por sua vez, destaca essas mesmas contribuições, mas restritas aos Estados-partes do MERCOSUL (Argentina, Brasil, Paraguai, Venezuela e Uruguai). Por fim, a seção 5 apresenta as análises dos dados e as conclusões.

\section{DEFINIÇÃO DE MPME: A NÃO ADOÇÃO DE UM CONCEITO HARMONIZADO}

Existem diferentes formas de conceituar MPME. A presente seção busca trazer à luz as diferentes definições adotadas pelos países mercosulinos, 
destacando que, embora o bloco já tenha elaborado conceito harmonizado, busca-se usá-lo apenas quando são adotadas políticas de natureza conjunta, sugerindo que ainda há muito em que evoluir nesse sentido.

Definir as MPME é tarefa árdua, pois existem inúmeros conceitos. De acordo com Salazar (2014, p. 12), isso é reflexo "[...] das necessidades de cada país, da conformação específica das empresas e da facilidade de classificação e obtenção de informações". Geralmente, os países adotam definições baseadas em uma ou mais das seguintes variáveis: número de empregados, valores das vendas, investimentos em ativos, tamanho do mercado, valor agregado, volume produzido, funções básicas da empresa e montante do capital investido.

Um estudo realizado por Saavedra e Hernández (2008, p. 133) indica que, entre os países latino-americanos, 85\% usam o número de empregados como principal variável de classificação, seguido de vendas anuais, com 62\% (como critério único ou combinado com outro), e do total de ativos, com 38\% (como critério único ou combinado com outro). As autoras indicam que o número de empregados é mais usado em função da "[...] facilidade de conhecer este dado e, desse modo, ter um parâmetro acessível de classificação".

Todos os países mercosulinos usam o número de empregados e as vendas como critério de classificação. No Uruguai, encontra-se o conceito de MPME, no Decreto Lei 504, de janeiro de 2007 (FERREIRA, 2011). As microempresas possuem até 4 empregados e vendas anuais de até UI2 milhões (dois milhões de unidades indexadas) ${ }^{1}$, já as pequenas empresas possuem de 5 a 19 empregados e vendas anuais de até UI 10 milhões, e as médias empresas possuem de 20 a 99 empregados e vendas anuais de até UI 75 milhões.

No Paraguai, a Lei $\mathrm{n}^{\mathrm{9}}$ 4.457, de 16 de maio de 2012, estabelece que o conceito microempresas compreende as empresas com até 10 funcionários e, no máximo, G 500 milhões (quinhentos milhões de guaranis). As pequenas empresas podem ter até 30 funcionários e, no máximo, G 2,5 bilhões (dois bilhões e quinhentos milhões de guaranis). Já as médias empresas possuem até 50 funcionários e, no máximo, G 6 bilhões (6 bilhões de guaranis) (PARAGUAY, 2012).

Na Argentina, a Resolução 21/2010, da Secretaria da Pequena e Média Empresa e Desenvolvimento Regional (em espanhol SEPYME), estabeleceu que são consideradas micro, pequenas e médias empresas aquelas cujas vendas totais, expressas em pesos argentinos (\$), não superem os valores estabelecidos na Tabela 1, que se detalha a seguir.

A Unidade Indexada (UI) equivalia a 2,1759 pesos uruguaios, à época do estudo de Ferreira (2011). 
Tabela 1 - Classificação das MPME segundo vendas totais expressas em pesos (\$) por atividades

\begin{tabular}{|c|c|c|c|c|c|}
\hline \multicolumn{6}{|c|}{ Setor } \\
\hline $\begin{array}{l}\text { Classifi- } \\
\text { cação }\end{array}$ & $\begin{array}{l}\text { Agropecuá- } \\
\text { rio }\end{array}$ & $\begin{array}{l}\text { Indústria } \\
\text { e minério }\end{array}$ & Comércio & Serviços & Construção \\
\hline $\begin{array}{c}\text { Microem- } \\
\text { presa }\end{array}$ & $\begin{array}{c}\text { Até } \\
610.000,00\end{array}$ & $\begin{array}{c}\text { Até } \\
1.800 .000,00\end{array}$ & $\begin{array}{c}\text { Até } \\
2.400 .000,00\end{array}$ & $\begin{array}{c}\text { Até } \\
590.000,00\end{array}$ & $\begin{array}{c}\text { Até } \\
760.000,00\end{array}$ \\
\hline $\begin{array}{l}\text { Pequena } \\
\text { empresa }\end{array}$ & $\begin{array}{c}610.000,01 \\
a \\
4.100 .000,00\end{array}$ & $\begin{array}{c}1.800 .000,01 \\
a \\
10.300 .000,00\end{array}$ & $\begin{array}{c}2.400 .000,01 \\
a \\
14.000 .000,00\end{array}$ & $\begin{array}{c}590.000,01 \\
a \\
4.300 .000,00\end{array}$ & $\begin{array}{c}760.000,01 \\
a \\
4.800 .000,00\end{array}$ \\
\hline $\begin{array}{c}\text { Média } \\
\text { empresa }\end{array}$ & $\begin{array}{c}4.100 .000,01 \\
a \\
24.100 .000,00\end{array}$ & $\begin{array}{c}10.300 .000,01 \\
a \\
82.200 .000,00\end{array}$ & $\begin{array}{c}14.000 .000,01 \\
a \\
111.900 .000,00\end{array}$ & $\begin{array}{c}4.300 .000,01 \\
a \\
28.300 .000,00\end{array}$ & $\begin{array}{c}4.800 .000,01 \\
a \\
37.700 .000,00\end{array}$ \\
\hline
\end{tabular}

Fonte: SEPYME (2010)

Entretanto, modificações foram introduzidas, dado que a SEPYME (2013) atualizou os valores máximos das vendas anuais usadas como base para a classificação das médias empresas, por meio da Resolução SEPYME n 50/2013. Atualmente, os valores máximos das vendas anuais para estas empresas são os definidos na Tabela 2.

Tabela 2 - Valores máximos das vendas anuais em pesos (\$) estabelecidos pela SEPYME para ser considerada média empresa por setor de atividade

\begin{tabular}{c|c|c|c|c|c}
\hline $\begin{array}{c}\text { Classifi- } \\
\text { cação }\end{array}$ & $\begin{array}{c}\text { Agropecuá- } \\
\text { rio }\end{array}$ & $\begin{array}{c}\text { Indústria e } \\
\text { mineração }\end{array}$ & Comércio & Serviços & Construção \\
\hline $\begin{array}{c}\text { Médias } \\
\text { empresas }\end{array}$ & $\begin{array}{c}4.100 .000,01 \\
\text { a }\end{array}$ & $\begin{array}{c}10.300 .000,01 \\
\text { a }\end{array}$ & $\begin{array}{c}14.000 .000,01 \\
\text { a }\end{array}$ & $\begin{array}{c}4.300 .000,01 \\
\text { a }\end{array}$ & $\begin{array}{c}4.800 .000,01 \\
\text { a }\end{array}$ \\
& $54.000 .000,00$ & $183.000 .000,00$ & $250.000 .000,00$ & $63.000 .000,00$ & $84.000 .000,00$ \\
\hline
\end{tabular}

Fonte: SEPYME (2013)

Foram empreendidas também mudanças relativas ao período considerado para se apurar o valor máximo das vendas anuais: aumentou-se o percentual de exportações, que pode ser deduzido deste; modificou-se o entendimento de quais empresas podem ser consideradas pequenas ou médias segundo a composição de sua propriedade; introduziu-se o cinema como indústria; e alterou-se a forma de cálculo do valor das vendas médias anuais nos casos em que a "idade da empresa" é inferior ao tempo necessário para o cálculo da quantia em análise. Entre os motivos que induziram as modificações está a pressão empresarial com vista ao acesso aos programas de apoio à competitividade e benefícios para as 
MPME, assim como mudanças na estrutura econômica setorial.

No Brasil, dois tipos de classificação se destacam. A Lei Complementar $n^{\circ}$ 123, de 14 de dezembro de 2006, ou o Estatuto das Microempresas e das Empresas de Pequeno Porte (EPP), usa como variável de classificação a Receita Bruta Anual $^{2}$ (BRASIL, 2011). Nos incisos I e II, e no caput do Art. $3^{\circ}$, diz-se que:

Art. $3^{\circ}$ Para os efeitos desta Lei Complementar, consideram-se microempresas ou empresas de pequeno porte, a sociedade empresária, a sociedade simples, a empresa individual de responsabilidade limitada e o empresário a que se refere o art. 966 da Lei n ${ }^{\circ} 10.406$, de 10 de janeiro de 2002 (Código Civil), devidamente registrados no Registro de Empresas Mercantis ou no Registro Civil de Pessoas Jurídicas, conforme o caso, desde que:

I - no caso da microempresa, aufira, em cada ano-calendário, receita bruta igual ou inferior a $\mathrm{R} \$ 360.000,00$ (trezentos e sessenta mil reais); e

II - no caso da empresa de pequeno porte, aufira, em cada ano-calendário, receita bruta superior a $R \$ 360.000,00$ (trezentos e sessenta mil reais) e igual ou inferior a $\mathrm{R} \$ 3.600 .000,00$ (três milhões e seiscentos mil reais).

Complementarmente, a mesma Lei define Micro Empreendedor Individual (MEI), no Parágrafo Primeiro, art. 18 - A, Seção III, Capítulo IV. O estatuto assim estabelece:

$\int 1^{\circ}$ Para os efeitos desta Lei Complementar, considera-se MEI o empresário individual a que se refere o art. 966 da Lei n ${ }^{\circ}$ 10.406, de 10 de janeiro de 2002 (Código Civil), que tenha auferido receita bruta, no ano- calendário anterior, de até $\mathrm{R} \$ 60.000,00$ (sessenta mil reais), optante pelo Simples Nacional e que não esteja impedido de optar pela sistemática prevista neste artigo.

Existe ainda, no caso brasileiro, a classificação dos portes das empresas que considera a variável número de pessoas ocupado e o setor do qual elas fazem parte (Tabela 3). A existência de mais de um conceito em um mesmo país é comum de ser encontrada, encontram-se até mesmo países que ainda não possuem conceitos que englobem as MPMEs de todos os setores da economia, como no caso venezuelano.

\footnotetext{
Segundo o parágrafo primeiro do mesmo artigo: "Considera-se receita bruta, para fins do disposto no caput deste artigo, o produto da venda de bens e serviços nas operações de conta própria, o preço dos serviços prestados e o resultado nas operações em conta alheia, não incluídas as vendas canceladas e os descontos incondicionais concedidos".
} 
Tabela 3 - Classificação dos estabelecimentos segundo o número de ocupados e setor da economia

\begin{tabular}{l|l|l}
\hline \multirow{2}{*}{\multicolumn{1}{c|}{ Porte }} & \multicolumn{2}{c}{ Setores } \\
\cline { 2 - 3 } & \multicolumn{1}{|c}{ Indústria $^{(1)}$} & \multicolumn{1}{c}{ Comércio e serviços ${ }^{(2)}$} \\
\hline Microempresa & até 19 pessoas ocupadas & até 9 pessoas ocupadas \\
\hline Pequena empresa & de 20 a 99 pessoas ocupadas & de 10 a 49 pessoas ocupadas \\
\hline Média empresa & de 100 a 499 pessoas ocupadas & de 50 a 99 pessoas ocupadas \\
\hline Grande empresa & 500 pessoas ocupadas ou mais & 100 pessoas ocupadas ou mais \\
\hline
\end{tabular}

Fonte: Elaborado pelos autores com base nos dados do Serviço Brasileiro de Apoio às Micro e Pequenas Empresas (SEBRAE, 2013, p. 17)

Nota: (1) As mesmas delimitações de porte foram utilizadas para o setor de construção;

(2) O setor serviços não inclui administração pública e serviços domésticos.

As definições na Venezuela requerem certo cuidado, pois se tem o conceito de Pequena e Média Indústria (PMI) ${ }^{3}$ e microempresas, mas não o conceito amplo de Pequenas e Médias Empresas, incorporando outros setores da atividade econômica (serviços, comércio e setor agrícola) (BRAVO, 2013). Os critérios utilizados para definir PMI e microempresas também são pessoas ocupadas e o faturamento anual, em Unidades Tributárias (UT): as microempresas/ microempresários possuem até 10 pessoas e vendas de UT 9.000; as pequenas indústrias possuem entre 11 e 50 pessoas e vendas entre UT 9.001 e 100.000; e as médias indústrias possuem entre 51 e 100 pessoas e vendas entre UT 100.001 e 250.000 (BRAVO, 2013).

De acordo com Bravo (2013), existe a necessidade de construir um conceito que considere todos os setores dos quais as MPME fazem parte. O autor propõe definição na qual o número de trabalhadores é critério básico, dadas as dificuldades em encontrar informações confiáveis e disponíveis sobre faturamento e investimentos da empresa. Por este entendimento, as PME venezuelanas são classificadas a partir do número de trabalhadores indicados acima e, complementarmente, usam-se dados sobre faturamento, vendas e média de solicitações de financiamento junto às instituições financeiras.

O MERCOSUL já elaborou conceito de MPME, isto é, conceito harmonizado, o qual se tenta usar quando da adoção de programas de natureza comum em nível do bloco. Desta forma, "nos Estados Partes do MERCOSUL são utilizadas diversas definições para delimitar este universo, o que demonstra a heterogeneidade de critérios respondendo a natureza própria do fenômeno MPME" (MERCOSUL, 1998). Os critérios de classificação também são o

3 Restringe-se ao setor industrial. 
número de trabalhadores e a receita anual, continuando predominantemente quantitativos.

As evoluções do conceito podem ser acompanhadas pelo estudo da Resolução GMC RES. No 90/93 (Política de apoio às micro, pequenas e médias empresas do MERCOSUL) e da Resolução GMC n 59/98 (políticas de apoio às micro, pequenas e médias empresas do MERCOSUL - etapa II). Ambas as resoluções refletem o esforço para encontrar uma definição que seja comum e aplicada aos Estados-parte, ao mesmo tempo em que se consideram as peculiaridades empresariais de cada país e as necessidades do bloco (MERCOSUR, 1993; MERCOSUL, 1998). Nesse sentido, segundo a Resolução GMC n 59/98, tem-se as definições resumidas na Tabelas 4 e 5 .

Tabela 4 - Conceito de MPME industriais segundo Resolução GMC 59/98

\begin{tabular}{|c|c|c|}
\hline \multicolumn{3}{|c|}{ Indústria } \\
\hline Tamanho & $\begin{array}{c}\text { Pessoal ocupado } \\
\text { De - até }\end{array}$ & $\begin{array}{c}\text { Vendas anuais US\$ } \\
\text { De - até }\end{array}$ \\
\hline Micro & $1-10$ & $1-400.000$ \\
\hline Pequena & $11-40$ & $400.001-3.500 .000$ \\
\hline Média & $41-200$ & $3.500 .001-20.000 .000$ \\
\hline
\end{tabular}

Fonte: MERCOSUL (1998)

Tabela 5 - Conceito de MPME do setor de comércio e serviços segundo Resolução GMC 59/98

\begin{tabular}{l|c|c}
\hline \multicolumn{3}{c}{ Comércio e serviços } \\
\hline Tamanho & $\begin{array}{c}\text { Pessoal ocupado } \\
\text { De }- \text { até }\end{array}$ & $\begin{array}{c}\text { Vendas anuais US\$ } \\
\text { De }- \text { até }\end{array}$ \\
\hline Micro & $1-5$ & $1-200.000$ \\
\hline Pequena & $6-30$ & $200.001-1.500 .000$ \\
\hline Média & $31-80$ & $1.500 .001-7.000 .000$ \\
\hline
\end{tabular}

Fonte: MERCOSUL (1998)

\section{ANÁLISE SOBRE A RELEVÂNCIA DAS MPME}

Embora as definições sobre as MPME divirjam, não apenas no âmbito do MERCOSUL, essas empresas contribuem significativamente para o crescimento econômico e para o desenvolvimento dos países. A presente seção objetiva expor essa relevância.

Observa-se a relevância deste segmento, inclusive fora das fronteiras nacionais, em termos de contribuição para o Produto Interno Bruto (PIB) e 
para diversos indicadores, como o número de empresas, geração de empregos, inovação, desenvolvimento e integração regional, estabilidade social, internacionalização econômica, valor industrial adicionado, receitas fiscais, pedidos de patentes, novos produtos, modernização e urbanização da economia, fortalecimento das cadeias globais de valor, criação de clusters industriais, redução da pobreza e distribuição de renda (ZHAO, 2010; CSE, 2008; OECD, 2009, 2012; LIU, 2009; CARDOZA; FORNES, 2013; CUNNINGHAM, 2011; CFED, 2004). Certamente, são vários os resultados positivos da participação das MPME na economia, mas, em função do escopo desse artigo, apenas alguns dos pontos supramencionados serão destacados.

Quando à contribuição das MPME, é analisada isoladamente. Tem-se a impressão de que se trata de algo irrelevante, tanto em termos de crescimento econômico quanto de desenvolvimento social. Porém, quando reunidas, estas empresas podem "[...] dirigir o desenvolvimento econômico em nível nacional, regional e global" (OECD, 2009, p. 7). Elas constituem "[...] o motor do crescimento e da criação de empregos na maior parte das economias do mundo" (INDRAWATI, 2013, p. v).

Segundo relatório da OECD (2000), as MPME são a força da economia local e seu alcance pode ser global. Enquanto força local, nos países de baixa renda, estas empresas contribuem com 78\% dos empregos, 67\% naqueles de renda média, 59\% nos de renda média alta e 66\% nos de renda alta (DALBERG, 2011). Na União Europeia (UE) são vistas como a espinha dorsal da economia, à medida que somam mais de 20,7 milhões de empresas, o equivalente a $98 \%$ do número total de empresas do bloco e mais $67 \%$ do número total de empregos (EUROBAROMETER, 2013).

Amestoy (2009) defende que as MPME são importantes tanto para a Europa quanto para a América Latina em função de sua capacidade de promover desenvolvimento mais inclusivo e sustentável, a distribuição de renda, a coesão social e maior democracia. No Peru, conforme Saavedra e Hernández (2008), as MPME são, por exemplo, as empresas que mais empregam pessoas maiores de 55 anos, grupo que geralmente enfrenta problemas de inserção/reinserção no mercado de trabalho.

Os números relativos à importância das MPME para a região são significativos (SAAVEDRA; HERNÁNDEZ, 2008; SALAZAR, 2014). Em média, considerando países como Argentina, Bolívia, Brasil, Chile, Colômbia, Costa Rica, El Salvador, Guatemala, México, Panamá, Peru, Uruguai e Venezuela, estes empreendimentos somam 97\% das unidades econômicas. No geral, as microempresas correspondem à maior parte deste total, aproximadamente $90 \%$, contra $9,5 \%$ de pequenas e médias empresas. 
No que se refere ao alcance das MPME fora das fronteiras locais e nacionais, destacam-se os ganhos de sua participação em redes, clusters industriais, cadeias globais de valor e outras parcerias. Adicionalmente, as MPME são importantes na superação de crises, como a atual crise financeira global (CFG); podem contribuir para o aprofundamento do processo de integração regional; e até mesmo podem se tornar um ator essencial na mudança do padrão de desenvolvimento de regiões como a América Latina.

Tomando como exemplo iniciativas de países europeus, uma das medidas que estão sendo usadas pela União Europeia para superar os efeitos nefastos da CFG é a tentativa de concretizar todos os benefícios potenciais que podem ser providos pelas MPME, por isso, elas passaram a estar no topo da agenda política do bloco. A CSE (2008, p. 2) expõe que:

A nossa capacidade para utilizar o potencial de crescimento e inovação das pequenas e médias empresas (PME) será, por isso, decisiva para a prosperidade futura da UE. Em um contexto global em permanente mutação, caracterizado por mutações estruturais contínuas e pressões concorrenciais acentuadas, o papel das PME na nossa sociedade passou a ser ainda mais importante enquanto fornecedores de oportunidades de emprego e agentes-chave do bem-estar das comunidades locais e regionais. O dinamismo das PME tornará a Europa mais robusta para fazer face à incerteza que pesa sobre o mundo globalizado de hoje.

As MPME também contribuem com o processo de integração regional. Estudo realizado por Harvie (2009), tendo como base a Ásia, defende que elas são importantes estrategicamente para o desenvolvimento econômico, para o crescimento e para a integração da região da Ásia Oriental e APEC (em inglês, Asia-Pacific Economic Cooperation). Segundo o autor, os Estados da região estão buscando cada vez mais concretizar a contribuição potencial destas empresas, em termos de geração de renda e empregos, e aumento das exportações, dos investimentos e do crescimento econômico. Igualmente, os Estados acreditam em sua contribuição para a amenização da pobreza nos países em desenvolvimento e para o aumento da competitividade regional de economias desenvolvidas.

A constituição e a consolidação de espaços de integração regional, do mesmo modo, podem contribuir com o desenvolvimento das MPME. A pesquisa desenvolvida por Hegge (2002) mostrou que a instituição da União Econômica e Monetária Europeia impactou positivamente sobre estas empresas. O alargamento do mercado regional, a remoção de barreiras não tarifárias, a introdução de programas de cooperação para as empresas da EU e as mudanças nas leis antitrustes, além de estimularem as transações transfronteiriças (por 
exemplo, comércio e investimentos), dado a modificação das vantagens específicas dos países do bloco, também alteraram as vantagens específicas das empresas.

Por conseguinte, as MPME também podem ser protagonistas na promoção da mudança estrutural requerida pela América Latina em seu processo de desenvolvimento (OECD/UN-ECLAC, 2012). Apesar do progresso alcançado nos últimos anos, a fundação econômica da região é baseada na fabricação de produtos de baixo valor agregado e na exploração de recursos naturais destinados à exportação, os quais são voláteis à redução da demanda externa e à variação dos preços das matérias-primas. Essa fraqueza estrutural gerada pela excessiva dependência da organização produtiva regional pode ser melhorada com investimentos no desenvolvimento do segmento de MPME. A ideia é que estes investimentos possam aumentar a produtividade e a competitividade da região, e elevar ao máximo o potencial das empresas de criar empregos de boa qualidade.

\section{AS MICRO, PEQUENAS E MÉDIAS EMPRESAS NOS PAÍSES DO MERCOSUL}

A partir do exposto acima, busca-se nesta seção analisar a atuação e a relevância das MPME nos países que compõem o MERCOSUL. Para Gatto (1999, p. 63), o MERCOSUL é um desafio para as pequenas e médias empresas. Ambas estariam "[...] expostas às consequências do processo de integração, tanto através da abertura de novas oportunidades de comércio e produção quanto através do aumento da ameaça e pressão competitiva de empresas de outros países”.

Novas oportunidades se abrem para as MPME, principalmente aquelas resultantes do mercado expandido com tratamento especial (GATTO, 1999) e da promoção de iniciativas conjuntas, diretas ou indiretas, visando melhor explorar as capacidades reais e potenciais destas empresas, tais como o Programa de Integração Produtiva do MERCOSUL, o Fundo MERCOSUL de Garantias para Micro, Pequenas e Médias Empresas, os projetos do Fundo para a Convergência Estrutural do MERCOSUL (Focem), o Acordo de Complementação Econômica 18 (ACE 18, de 2001), a integração produtiva das PME do setor de autopeças, entre outras.

Destacando a importância das MPME para os países membro do MERCOSUL, tem-se que, no Uruguai, o segmento constitui “o sistema nervoso" da economia do país (MIEM, 2012). Nas palavras de Ferreira (2011, p. 284-285), elas são empreendimentos “[...] especialmente relevantes no caso de um país pequeno como o Uruguai, [...] fundamental no tecido socioeconômico, sobretudo pelo efeito multiplicador que o bom desempenho destas empresas tem no emprego e nas economias locais". 
No país, dos 136.691 estabelecimentos considerados MPME, 84\% são microempresas, $13 \%$ são empresas de pequeno porte e apenas 3\% são médias empresas, totalizam, assim, 99,4\% de todas as empresas do país (MIEM, 2013; HUGHES, 2012; FERREIRA, 2011). Considerando os setores da economia, $53 \%$ destes estabelecimentos estão localizadas no setor de serviços, 37\% no setor comercial e $10 \%$ no setor industrial. Adicionalmente, no conjunto, empregam cerca de 60\% da mão-de-obra privada e contribuem com 40\% do PIB (HUGHES, 2012).

Segundo Ferreira (2011), dos 643.953 trabalhadores identificados no país em 2009, 24\% estava ocupado em microempresas, $21 \%$ em pequenas empresas, o mesmo que nas médias empresas, e 34\% em grandes empresas. O pessoal ocupado está distribuído principalmente no setor manufatureiro (18\% dos ocupados em microempresas, $20 \%$ dos ocupados em pequenas empresas e $23 \%$ dos ocupados em médias empresas) e no comércio (34\% dos ocupados em microempresas, $33 \%$ dos ocupados em pequenas empresas e $24 \%$ dos ocupados em médias empresas).

Adicionalmente, as MPME uruguaias também contribuem com questões sociais (MIEM, 2013). No país, cerca de 60\% do pessoal ocupado nestes estabelecimentos são mulheres. Estas estão principalmente inseridas no setor de serviços, no qual respondem por $62 \%$ do total. No comércio e na indústria representam $43 \%$ e $39 \%$ do pessoal ocupado respectivamente. Além disso, em mais da metade das empresas há mulheres nos cargos mais altos, principalmente nas médias empresas e no setor de serviços.

$\mathrm{Na}$ Venezuela, seguindo o conceito de Bravo (2013) de classificação das empresas venezuelanas, visto na seção 2, existem aproximadamente 420.000 empresas formais das quais $99,02 \%$ são MPME, e 0,8\% são grandes empresas (GE). O setor comercial é o mais representativo dos setores da atividade econômica entre as MPME, cerca de 60\% do total, seguido de serviços, com aproximadamente $33 \%$, e industrial, com cerca de $4 \%$.

Graterol e Rondón (2011), usando o conceito de pequenas e médias indústrias, -novamente esclarecendo que é diferente de PME, como exposto na seção 2 - indicam que as PMI, as quais representam aproximadamente 90\% dos estabelecimentos industriais do país, são responsáveis por apenas cerca de $36 \%$ do total de empregos no setor industrial. Adicionalmente, como se observa nos dados fornecidos por Bravo (2013), as PMI contribuem apenas com cerca de 4\% da atividade econômica do país. Estimando essa contribuição reduzida, Graterol e Rondón (2011, p. 385) afirmam que "considerando-se as cifras do subsetor que agrupa o comércio, transporte e os serviços em geral, obtém-se mais de dois terços do emprego formal [...]". 
No Paraguai, as MPME têm contribuído para a recuperação da economia. Ríos (2011) expõe que entre 2003-2008 elas foram essenciais para a geração de empregos em um momento em que a economia paraguaia estava se reerguendo. Elas foram as protagonistas, haja vista que lideraram a criação de novos postos de trabalho, principalmente nos setores de serviços e indústrias manufatureiras. Ao todo, geraram aproximadamente $43 \%$ dos novos empregos. Ainda segundo o autor, elas são salutares para o crescimento econômico inclusivo, sustentável e estável. Ramírez (2007) destaca que 68\% do emprego urbano e 90\% do emprego rural são gerados por MPME. Para ele, “[...] as PME são de suma importância no Paraguai, por um lado ao gerar empregos em uma quantidade importante e, por outro, ao oferecer melhores níveis de ingresso aos seus empregados". Por sua capacidade de gerar empregos Yeng, Sosa e Dissel (2007) destacam que as MPME podem ser decisivas na redução da pobreza neste país, considerado um dos mais pobres da região.

$\mathrm{Na}$ Argentina, as MPME também desempenham um papel relevante no modelo de crescimento econômico e na busca do desenvolvimento social. Segundo o Ministério da Indústria Argentina (MI, 2014), “as pequenas e médias empresas têm um papel preponderante dentro do modelo de crescimento econômico com inclusão social, e têm acompanhado o processo de expansão industrial mais importante da história argentina [...]". O segmento de MPME soma 99\% do total de empresas do país, o equivalente a 603 mil empresas $(10 \%$ industriais), sendo 229 mil criadas na última década; respondem por $60 \%$ dos empregos e $45 \%$ das vendas totais.

No Brasil, a relevância das micro e pequenas empresas (MPE) não é diferente. Segundo o SEBRAE (2013, p. 27), “apesar da moderação na atividade econômica brasileira no período recente, o segmento das micro e pequenas empresas ainda se expande no país, impulsionado pelo crescimento da renda e do crédito". Este segmento, que somava 4,8 milhões de estabelecimentos em 2002, passou a 6,3 milhões em 2012, crescimento de 30,9\% no período, e mesmo considerando a crise financeira global recente o número não se reduziu, embora o crescimento médio tenha diminuído. Enquanto no período em destaque o crescimento médio do número de estabelecimentos foi de 2,7\% a.a., entre 2002 e 2007 esse número foi de 2,9\% a.a., diminuindo para 2,5\% a.a. entre 2007 e 2012.

No que se refere à empregabilidade, em 2002 o segmento de MPE foi responsável por 9,5 milhões de empregos, enquanto o segmento de médias e grandes empresas (MGE) empregava 7,6 milhões, 1,9 milhões de empregos a menos. Em 2012 enquanto aquelas geraram 16,2 milhões de empregos, estas geraram 15,1 milhões, 1,1 milhões a menos. No período, as MPE criaram 6,6 
milhões de empregos com carteira assinada, um crescimento médio anual de 5,4\% a.a. (SEBRAE, 2013).

A relevância deste seguimento para a economia brasileira é ainda mais clara quando se constata que $99 \%$ dos estabelecimentos no país são MPE, as quais geraram 51,7\% dos empregos privados não agrícolas formais e aproximadamente $40 \%$ da massa salarial em 2012.

Setorialmente, o comércio é o setor com maior participação relativa de MPE, 49,4\% (3,1 milhões de estabelecimentos de MPE em 2012). Em seguida está o setor de serviços, com 34,6\% (2,2 milhões de estabelecimentos de MPE em 2012). A indústria responde a apenas 10,8\% do total de MPE (683 mil estabelecimentos de MPE em 2012). Por sua vez, o setor de construção é o de menor participação relativa com 5,1\% (325 mil estabelecimentos de MPE em 2012.).

A contribuição social das MPE também é relevante no Brasil. Neste segmento 2,8\% do total de ocupados são de pessoas com 65 anos ou mais, contra $0,6 \%$ nas GE. Da mesma forma, o segmento ocupa mais pessoas com baixa escolaridade, tendo em vista que $47,9 \%$ do total de ocupados é de analfabetos $(2,0 \%)$, pessoas com ensino fundamental incompleto $(26,0 \%)$ e pessoas com fundamental completo ou médio incompleto (19,9\%). A participação desses grupos entre os ocupados em MGE é bem menor, 28,7\%: analfabetos 0,8\%, pessoas com fundamental incompleto $13,0 \%$, e pessoas com fundamental completo ou médio incompleto 14,9\%. O número de ocupados com superior completo também é menor nas MPE, 11,5\% do total, contra 18,0\% nas MGE (SEBRAE, 2013).

Embora com dados positivos, indicando a contribuição econômica e social das MPME para os países que constituem o MERCOSUL, principalmente na geração de empregos, produção e estabilidade social, este segmento ainda contribui pouco quando se trata de exportação, mesmo considerando o mercado expandido com tratamento especial. De acordo com o Banco Interamericano de Desenvolvimento (BID, 2013), isso se explica por problemas de competitividade nas economias das quais as MPME fazem parte, assim como por problemas resultantes do menor porte destes estabelecimentos. "Neste contexto, a melhora na inserção internacional destas empresas resulta crucial para fortalecer o desempenho exportador destes países, assim como para fortalecer os efeitos positivos das vendas externas sobre o resto da economia" (BID, 2013).

Ao se analisar os dados relativos à participação de pequenas e médias empresas exportadoras (PMEX) nas exportações dos países do MERCOSUL, observa-se participação relevante, porém o valor das vendas é relativamente 
baixo. Entretanto, apesar das maiores dificuldades de se posicionar e explorar mercados globais, as PMEX exportam mais produtos manufaturados do que as grandes empresas, nas quais predominam os produtos primários e baseados em recursos naturais. No Brasil, segundo dados do BID (2013), 46\% das exportações das PMEX são de produtos manufaturados, sendo de $1 / 3$ nas GE. As manufaturas de origem agropecuária e industrial na Argentina representam 81\% do valor exportado pelas PMEX do país, ao passo que nas grandes empresas esse valor é 2/3. No Paraguai, enquanto as GE exportam mais produtos tradicionais como soja, algodão e madeira, 2/3 das vendas externas das PMEX compreendem produtos não tradicionais.

Também é positiva a expectativa de maior participação das MPME no total de exportações dos países do MERCOSUL. O BID (2013) indica, ainda, que as vendas externas das PMEX brasileiras têm sido mais dinâmicas do que aquelas realizadas pelas GE, e na Argentina e no Uruguai o valor têm aumentado. Soma-se a isso o fato de que neste último país as PMEX começam a exportar mais cedo em comparação às GE, da mesma forma que objetivam continuar explorando oportunidades para além das fronteiras nacionais.

É importante frisar que o MERCOSUL apresenta muito mais oportunidades do que ameaças. As empresas que atuam em setores pouco competitivos possivelmente sofrem com o aumento da concorrência e devem se adaptar à nova realidade do mundo competitivo que a globalização trouxe para todas as economias do mundo. Por outro lado, as que são ou se tornarem competitivas e conseguirem realizar parcerias para fortalecer os negócios dentro do MERCOSUL podem aumentar as chances de serem bem-sucedidas. Outrossim, as próprias MPME podem ajudar a consolidar este bloco, dado a sua condição unificadora e principalmente sua crucial contribuição para o crescimento econômico e o desenvolvimento social.

\section{RESULTADOS E CONCLUSÕES}

Como foi destacado, a temática desse artigo foi o papel das MPME em países membros do MERCOSUL e buscou-se ensaiar resposta à questão: As MPME constituem atores relevantes na consolidação do espaço regional conformado pelas economias mercosulinas? Defendeu-se que sim, o que se mostra verdadeiro ao considerar as contribuições dessas empresas para os seus países e para fora deles.

É perceptível a importância das MPME. Os dados apresentados indicam que elas são promotoras de crescimento econômico (inclusivo, sustentável 
e estável), do desenvolvimento social e podem contribuir com a inserção dos países na economia internacional. Contribuem em termos de PIB, número de empresas, geração de empregos, inovação, desenvolvimento regional, estabilidade social, internacionalização econômica, valor industrial adicionado, receitas fiscais, pedidos de patentes, novos produtos, modernização e urbanização da economia, fortalecimento das cadeias globais de valor, criação de clusters industriais, redução da pobreza e distribuição de renda.

Os casos das MPME no âmbito da União Europeia, Ásia Oriental e APEC e América Latina também refletem a sua relevância em termos de superação de crises, mudança de padrão estrutural de desenvolvimento e, principalmente, em termos de promoção de maior integração regional.

É necessário destacar os desafios e as oportunidades geradas pelo mercado expandido com o tratamento especial dado às MPME. Ressalta-se também que esses empreendimentos também devem ser vistos como atores com capacidades reais e potenciais de contribuir para a consolidação do espaço regional mercosulino. Se dentro de cada país que participa do bloco for comprovada a relevância destas empresas, as iniciativas e as oportunidades de negócios certamente aumentarão a sua relevância.

Verifica-se, ainda, que os fatores impulsionadores da globalização são fortes e que atingiram uma dinâmica muito sofisticada, em particular o desenvolvimento tecnológico, que um país pequeno não tem qualquer possibilidade de se desenvolver e mesmo um país grande e rico, isoladamente, teria muita dificuldade em fazê-lo sem entrar na nova ordem mundial. Desta forma, as grandes empresas, se não querem ser vencidas pelos concorrentes, têm que adotar estratégias em uma escala que ultrapasse as fronteiras nacionais. Mas só isso não é suficiente. Entende-se a necessidade de que as empresas de menor porte também se posicionem diante deste cenário globalizado, com o intuito de achar um espaço em que possam ou competir com as grandes nacionais e multinacionais, ou fazer parte de suas cadeias produtivas, nesse caso aumentando ainda mais a inserção internacional de seu país de origem.

Por estes motivos, é fundamental começar um amplo debate sobre o papel das MPME para as economias nacionais e a sua contribuição para o processo de integração do MERCOSUL. Seria importante tornar as empresas de menor porte alvo de atenção prioritária por parte do governo. É necessário que a participação do governo seja mais ousada para poder concretizar os interesses da integração e resguardar um mercado prioritário para esses empreendimentos. Somente desta forma o sistema de integração vigente poderá evoluir com consistência. O esforço deve acontecer também por parte das empresas, preferencialmente constituindo- 
se do empenho conjunto a favor da consolidação e melhor aproveitamento do mercado mercosulino.

\section{REFERÊNCIAS}

AMESTOY, L. H. Políticas para las mipymes frente a la crisis: conclusiones de un estudio comparativo de América Latina y Europa. EuropeAid/Organización Internacional del Trabajo, 2009.

BID - Banco Interamericano de Desarrollo. Inserción internacional de las PYMES del MERCOSUR. Carta Mensal, n. 205, sept. 2013.

BRASIL. Lei Complementar n⿳ำ 123, de 14 de dezembro de 2006. Brasília: Planalto, 2011.

BRAVO, T. P. Tercer Observatorio de la Pequeña y Mediana Empresa de Venezuela. 3. ed. Tomás Páez Bravo, 2013.

CARDOZA, G.; FORNES, G. The international expansion of China's small- and medium-sized business: Status today and future outlook. Journal of Chinese Entrepreneurship, v. 5, n. 3, p. 252-273, 2013.

CFED - The Corporation for Enterprise Development. Desktop study: SMEs and poverty reduction. Washington, 2004.

CSE - Comissão das Comunidades Europeias. Comunicação da Comissão ao Parlamento Europeu, ao Conselho, ao Comité Económico e Social Europeu e ao Comité das Regiões: “Think SmallFirst" / Um "Small Business Act" para a Europa. Bruxelas, 2008.

CUNNINGHAM, L. X. SMEs as motor of growth: A review of China's SMEs development in thirty years (1978-2008). Amsterdam, Human Systems Management, v. 30, n. 1-2, p. 39-54, 2011.

DALBERG. Report on Support to SMEs in Developing Countries Through Financial Intermediaries. - Geneva: Dalberg, 2011.

EUROBAROMETER. SMEs, resource efficiency and green markets. Brussels: Flash Eurobarometer 381 - TNS Political \& Social/European Commission. 2013.

FERREIRA, C. Políticas e instituciones de apoyo a las MIPYME en Uruguay. In: FERRARO, Carlo (compilador). Apoyando a las pymes: Políticas de fomento en América Latina y el Caribe. Santiago de Chile: Naciones Unidas, 2011. 
GATTO, F. Mercosur: its challenges to small and medium-sized industrial enterprises in terms of competition. Cepal Review 68, p. 61-77, ago. 1999.

GRATEROL, A. J.; RONDÓN, L. M. Políticas e instituciones de apoyo a las pymes en Venezuela. In: FERRARO, Carlo (compilador). Apoyando a las pymes: Políticas de fomento en América Latina y el Caribe. Santiago de Chile: Naciones Unidas, 2011.

HARVIE, C. Regional integration in Asia and the contribution of SMEs - a Review of the key issues and policy imperatives. International Economics Studies, v. 34, n. 1 (New Issue), p. 19-44, Spring \& Summer 2009.

HEGGE, B. SMEs and European integration: Internationalisation strategies. London: Routledge, 2002.

HUGHES, C. (Directora). Encuesta nacional de mipymes comerciales, industriales y de servicios. Uruguay: MIEMDINAPYME/Equipos Mori, 2012.

INDRAWATI, S. M. Preface. Doing Business 2014: Understanding regulations for small and medium-size enterprises. Washington: World Bank Group, 2013. p. 5.

LIU, X. Impacts of the global financial crisis on small and medium enterprises in the People's Republic of China. ADBI, wp. 180. Tokyo: Asian Development Bank Institute, 2009.

MERCOSUL - Mercado Comum do Sul. MERCOSUL/GMC/RES № 59/98 - Políticas de Apoio às Micro, Pequenas e Médias Empresas do MERCOSUL - Etapa II, 1998. Disponível em: <http://www.sice.oas.org/trade/mrcsrs/ resolutions/Res5998p.asp>. Acesso em: 07 nov. 2014.

MERCOSUR - Mercado Común del Sur. MERCOSUR/GMC/RES № 90/93: Política de apoyo a las micropequeñas y medianas empresas del MERCOSUR, 1993. Disponível em: <http://www.sice.oas.org/trade/mrcsrs/resolutions/ Res9093.asp>. Acesso em: 07 nov. 2014.

MIEM - Ministerio de Industria, Energía y Minería. Encuesta nacional de las mipymes: Resumen Ejecutivo. Uruguay, 2013.

Encuesta nacional de mipymes comerciales, industriales y de servicios. Uruguay, 2012.

MI - Ministerio de Industria. Pymes argentinas: protagonistas del modelo productivo con inclusión, 2014. Disponível em: < http://www.industria.gob.ar/ pymes/\#>. Acesso em: 27 nov. 2014. 
OECD - Organization for Economic Co-operation and Development. Internationalisation of SMEs (Dimension 10): Encourage and support SMEs to benefit from the growth of markets (Small Business Act Principle 10). In: SME Policy Index: Eastern Partner Countries 2012: Progress in the Implementation of the Small Business Act for Europe. Paris: OECD Publishing, 2012.

Top barriers and drivers to SME Internationalization. - Paris:

OECD Centre for entrepreneurship, SME and local development (CFE), 2009.

Small and medium-sized enterprises: local strength, global reach. Paris, 2000.

OECD - Organization for Economic Co-operation and Development; UNECLAC - United Nations-Economic Commission for Latin America and The Caribbean. Latin American economic outlook 2013: SME policies for structural change. Paris and Santiago, 2012.

PARAGUAY. Ley n. 4.457 - Para las micro, pequeñas y medianas empresas (MIPYMES). Assunção, 16 de Mayo de 2012.

RAMÍREZ, J. Las PYMES exportadoras paraguayas: situación actual, perspectivas y desafíos. Asunción: Comisión Económica Para América Latina y el Caribe (CEPAL), 2007.

RÍOS, C. G. Lineamientos para una Política de Empleo en el Paraguay: Nuevos portes para las políticas públicas en Paraguay. Asunción: Centro de Análisis y Difusión de la Economía Paraguaya, CADEP, 2011.

SAAVEDRA, M.; HERNÁNDEZ, Y. Caracterización e importancia de las MIPYMES en Latinoamérica: Un estudio comparativo. Actualidad Contable FACES, Mérida: Venezuela, n. 17, jul.-dic., p. 122-134, 2008.

SALAZAR, A. L. La realidad de la micro, pequeña y mediana empresa en América Latina. In: SANTOY, Adolfo Rafael Rodríguez. Herramientas para la Competitividad de la Pequeña Empresa en America Latina. México Chile: Biblioteca Virtual, 2014. Capítulo 1: p. 10-31.

SEBRAE - Serviço Brasileiro de Apoio às Micro e Pequenas Empresas; DIEESE - Departamento Intersindical de Estatística e Estudos Socioeconômicos. Anuário do trabalho na micro e pequena empresa: 2013. 6. ed. Brasília, 2013.

SEPYME - Secretaría de la Pequeña y Mediana Empresa y Desarrollo Regional. Resolución 50/2013: Resolución № 24/2001 - Modificación. Ministerio de Economía y Finanzas Públicas - MECON - Argentina, 2013. Disponível em: 
<http://www.infoleg.gob.ar/infolegInternet/anexos/210000-214999/212683/ norma.htm>. Acesso em: 27 nov. 2014.

Resolução 21/2010: Modificación de la Resolución № 24/01 en relación con la determinación del valor de las ventas anuales. Ministerio de Economía y Finanzas Públicas - MECON - Argentina, 2010. Disponível em: <http://www.infoleg.gov.ar/infolegInternet/anexos/170000-174999/170679/ norma.htm>. Acesso em: 27 nov. 2014.

YENG, J. A.; SOSA, E.; DISSEL, S. C. V. Estudio legal sobre la participación de Micro y Pequeñas Empresas en las Contrataciones Públicas en el Paraguay. Asunción: Organización Internacional del Trabajo, 2007.

ZHAO, Y. Research on the approaches of the participation of China's SMEs in international trade under financial crisis. International Journal of Business and Management, Toronto, v. 5, n. 1, p. 69-73, 2010. 
